\title{
Corrigendum: Korean Medication Algorithm for Bipolar Disorder 2018 : Manic Episode
}

Young Sup Woo, MD, PhD ${ }^{1}$, Won-Myong Bahk, MD, PhD ${ }^{1}$, Bo-Hyun Yoon, MD, $\mathrm{PhD}^{2}$, Duk-In Jon, MD, PhD ${ }^{3}$, Jeong Seok Seo, MD, PhD ${ }^{4}$, Won Kim, MD, PhD ${ }^{5}$, Jung Goo Lee, MD, PhD ${ }^{6,7}$, Jong-Hyun Jeong, MD, PhD ${ }^{1}$, Moon-Doo Kim, MD, PhD ${ }^{8}$, InKi Sohn, MD, PhD ${ }^{9}$, Se-Hoon Shim, MD, PhD ${ }^{10}$, Hoo-Rim Song, MD, $\mathrm{PhD}^{11}$, Kyung Joon Min, MD, $\mathrm{PhD}^{12}$

${ }^{1}$ Department of Psychiatry, College of Medicine, The Catholic University of Korea, Seoul, ${ }^{2}$ Department of Psychiatry, Naju National Hospital, Naju, ${ }^{3}$ Department of Psychiatry, Sacred Heart Hospital, Hallym University, Anyang, ${ }^{4}$ Department of Psychiatry, School of Medicine, Konkuk University, Chungju, ${ }^{5}$ Department of Psychiatry, Seoul Paik Hospital, College of Medicine, Inje University, Seoul, ${ }^{6}$ Department of Psychiatry, Haeundae Paik Hospital, College of Medicine, Inje University and Paik Institute for Clinical Research, ${ }^{7}$ Department of Health Science and Technology, Graduate School of Inje University, Busan, ${ }^{8}$ Department of Psychiatry, Jeju National University Hospital, Jeju, ${ }^{9}$ Department of Psychiatry, Keyo Hospital, Keyo Medical Foundation, Uiwang, ${ }^{10}$ Department of Psychiatry, Soonchunhyang University Cheonan Hospital, Soonchunhyang University, Cheonan, ${ }^{11}$ Department of Psychiatry, Myongii Hospital, Goyang, ${ }^{12}$ Department of Psychiatry, College of Medicine, Chung-Ang University, Seoul, Korea

Mood Emot 2018;16(1):13-24

http://www.moodandemotion.org/journal/view.html?uid=2\&vmd=Full

We discovered a typographic error in "Korean Medication Algorithm for Bipolar Disorder 2018 : Manic Episode. Mood Emot 2018;16(1):13-24". The authors wish to correct a typographic error that was discovered in Fig. 1B. We apologizes for any inconvenience that it may have caused.

The text in the top box of Fig. 1B "Manic episode without psychotic features" should be corrected into "Manic episode with psychotic features".

Received May 13, 2021, Revised May 17, 2021, Accepted May 17, 2021

Correspondence: Won-Myong Bahk, MD, PhD

Department of Psychiatry, Yeouido St. Mary's Hospital, College of Medicine, The Catholic University of Korea, 10 63-ro, Yeongdeungpo-gu, Seoul 07345, Korea

TEL +82-2-3779-1051 E-mail wmbahk@catholic.ac.kr ORCID https://orcid.org/0000-0002-0156-2510

Co-Correspondence: Kyung Joon Min, MD, PhD

Department of Psychiatry, College of Medicine, Chung-Ang University, 102, Heukseok-ro, Dongjak-gu, Seoul 06973, Korea

TEL +82-2-6299-1521 E-mail kjoonmin@gmail.com ORCID https://orcid.org/0000-0001-7037-8904

Copyright $@$ by Korean Society for Affective Disorders.

This is an Open Access article distributed under the terms of the Creative Commons Attribution Non-Commercial License (http://creativecommons.org/licenses/ by-nc/4.0/) which permits unrestricted non-commercial use, distribution, and reproduction in any medium, provided the original work is properly cited. 
Before correction:

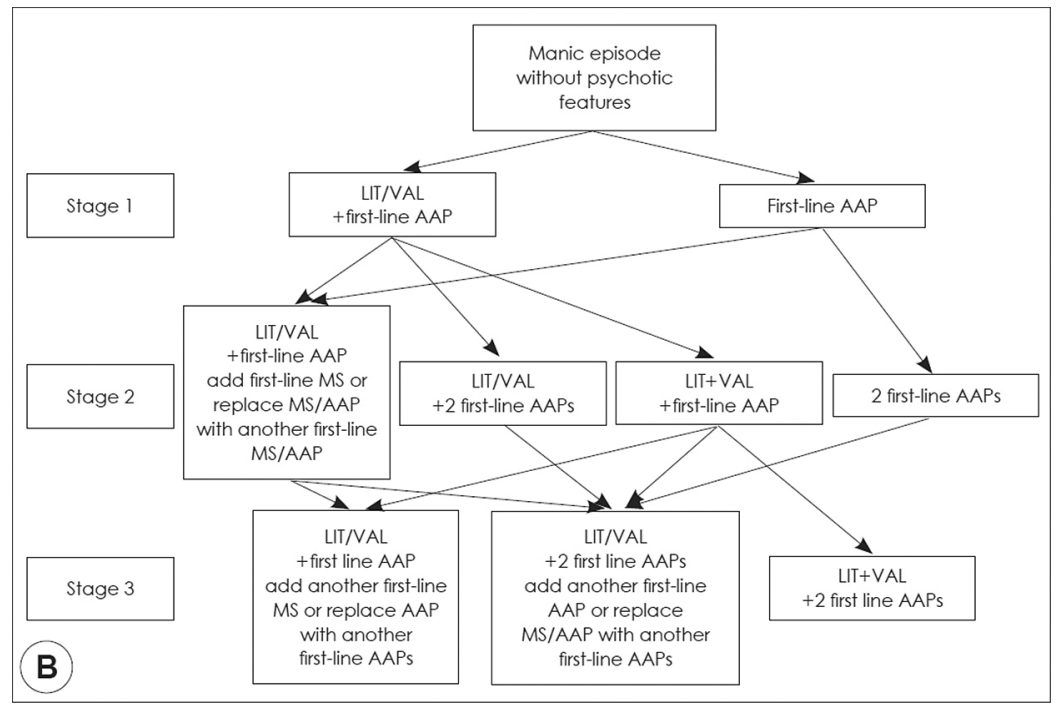

The Fig. 1B should be corrected as follows:

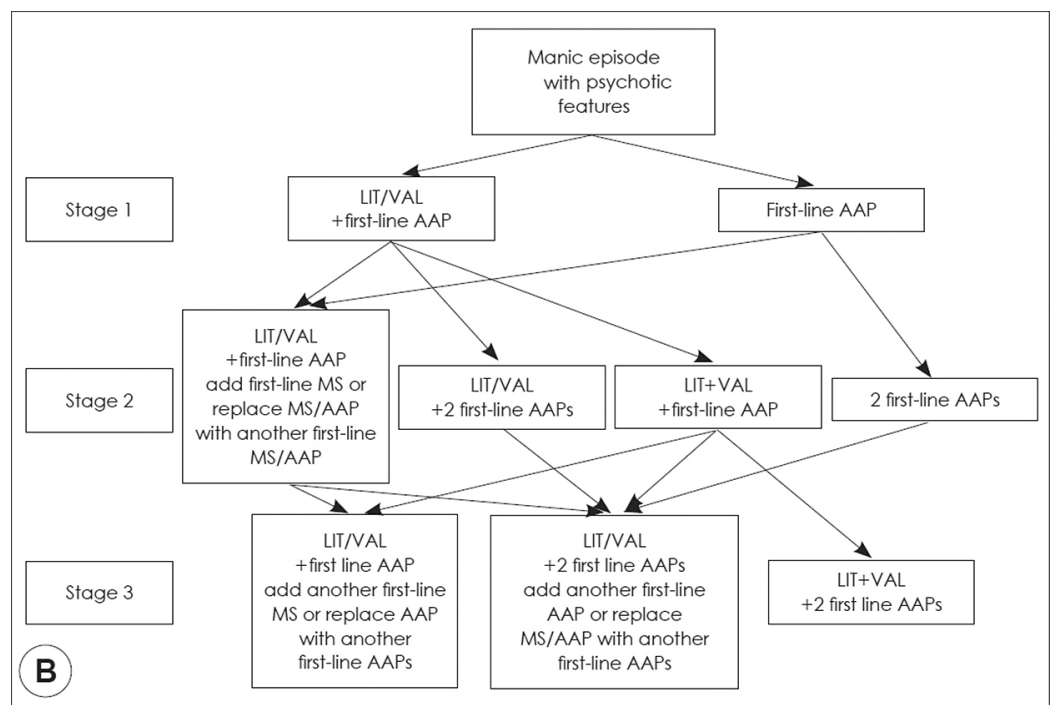

